\title{
Cesarean Section or Vaginal Delivery to Prevent Possible Vertical Transmission From a Pregnant Mother Confirmed With COVID-19 to a Neonate: A Systematic Review
}

OPEN ACCESS

Edited by:

Susan Christina Welburn,

University of Edinburgh,

United Kingdom

Reviewed by:

Lefei Han,

Hong Kong Polytechnic University,

Hong Kong

Yanting Wu,

International Peace Maternity and

Child Health Hospital, China

*Correspondence:

Jianghui $\mathrm{Ca}$

776773221@qq.com

†These authors have contributed equally to this work and share first authorship

Specialty section:

This article was submitted to Infectious Diseases - Surveillance,

Prevention and Treatment, a section of the journal

Frontiers in Medicine

Received: 01 December 2020 Accepted: 22 January 2021

Published: 17 February 2021

Citation:

Cai J, Tang M, Gao Y, Zhang H, Yang $Y$, Zhang $D$, Wang $H$, Liang $H$, Zhang $R$ and Wu B (2021) Cesarean Section or Vaginal Delivery to Prevent Possible Vertical Transmission From a

Pregnant Mother Confirmed With COVID-19 to a Neonate: A Systematic

Review. Front. Med. 8:634949.

doi: 10.3389/fmed.2021.634949

\begin{abstract}
Jianghui Cai ${ }^{* t}$, Mi Tang ${ }^{2 \dagger}$, Yu Gao ${ }^{1 \dagger}$, Hongxi Zhang ${ }^{1 \dagger}$, Yanfeng Yang ${ }^{3}$, Dan Zhang ${ }^{1}$, Han Wang ${ }^{1}$, Hua Liang ${ }^{1}$, Rui Zhang ${ }^{1}$ and $B o W^{1}{ }^{1}$

${ }^{1}$ Department of Pharmacy, Chengdu Women's and Children's Central Hospital, School of Medicine, University of Electronic Science and Technology of China, Chengdu, China, ${ }^{2}$ Office of Good Clinical Practice, Chengdu Women's and Children's Central Hospital, School of Medicine, University of Electronic Science and Technology of China, Chengdu, China, ${ }^{3}$ Department of Pediatric Cardiology, Chengdu Women's and Children's Central Hospital, School of Medicine, University of Electronic Science and Technology of China, Chengdu, China
\end{abstract}

Background: The impact of delivery mode on the infection rates of Coronavirus disease 2019 (COVID-19) in the newborn remains unknown. We aimed to summarize the existing literature on COVID-19 infection during pregnancy to evaluate which mode of delivery is better for preventing possible vertical transmission from a pregnant mother confirmed with COVID-19 to a neonate.

Methods: We performed a comprehensive literature search of PubMed, Embase, Cochrane Library, Web of Science, Google Scholar, and the Chinese Biomedical Literature database (CBM) from 31 December 2019 to 18 June 2020. We applied no language restrictions. We screened abstracts for relevance, extracted data, and assessed the risk of bias in duplicate. We rated the certainty of evidence using the GRADE approach. The primary outcome was severe acute respiratory syndrome coronavirus 2 (SARS-CoV-2) test positivity in neonates born to mothers with confirmed COVID-19 following different delivery modes. Secondary outcomes were neonatal deaths and maternal deaths. This study is registered with PROSPERO, CRD42020194049.

Results: Sixty-eight observational studies meeting inclusion criteria were included in the current study, with no randomized controlled trials. In total, information on the mode of delivery, detailed neonatal outcomes, and SARS-CoV-2 status were available for 1,019 pregnant women and 1,035 neonates. Six hundred and eighteen (59.71\%) neonates were born through cesarean section and $417(40.29 \%)$ through vaginal delivery. Probable congenital SARS-CoV-2 infections were reported in 34/1,035 (3.29\%) neonates. Of babies born vaginally, $9 / 417$ (2.16\%) were tested positive compared with 25/618 (4.05\%) born by cesarean. Of babies born vaginally, 0/417 (0.00\%) neonatal deaths were reported compared with $6 / 618(0.97 \%)$ born by cesarean. Of women who delivered vaginally, $1 / 416(0.24 \%)$ maternal deaths were reported compared with 11/603 (1.82\%) delivered by cesarean. Two women died before delivery. Sensitivity analyses and subgroup analyses showed similar findings. 
Conclusions: The rate of neonatal COVID-19 infection, neonatal deaths, and maternal deaths are no greater when the mother gave birth through vaginal delivery. Based on the evidence available, there is no sufficient evidence supporting that the cesarean section is better than vaginal delivery in preventing possible vertical transmission from a pregnant mother confirmed with COVID-19 to a neonate. The mode of birth should be individualized and based on disease severity and obstetric indications. Additional good-quality studies with comprehensive serial tests from multiple specimens are urgently needed.

\section{Study registration: PROSPERO CRD42020194049.}

Keywords: coronavirus disease 2019, COVID-19, SARS-CoV-2, pregnancy, mode of delivery, vertical transmission

\section{INTRODUCTION}

Since the outbreak of a cluster of patients with pneumonia of unknown cause in Wuhan, Hubei Province, China in December 2019 (1). The disease was later named Coronavirus disease 2019 (COVID-19), caused by the novel severe acute respiratory syndrome coronavirus 2 (SARS-CoV-2) quickly spreading in China and other countries (2).

COVID-19 is the third coronavirus outbreak in the twentyfirst century, and the other two are severe acute respiratory syndrome coronavirus (SARS-CoV) outbreaks in 2002 and Middle East respiratory syndrome coronavirus (MERS-CoV) outbreaks in 2012 (3-5), both can cause severe complications during pregnancy (6-9). Pregnant women might be at increased risk of severe infections considering that the COVID-19 seems to have a similar pathogenic potential as SARS-CoV and MERSCoV. Pregnant women are generally susceptible to COVID-19 considering they are in a particular state of immune suppression and more susceptible to respiratory pathogens $(10,11)$. Because of decreased lung volumes caused by increases in uterus size during pregnancy, patients might be more prone to have a more rapid clinical deterioration with COVID-19 during pregnancy, which may increase the risk of adverse pregnancy outcomes.

There is a concern about the vertical transmission of SARSCoV-2 due to the limited data on COVID-19 (12). Until now, vertical transmission from a pregnant mother confirmed with COVID-19 to a neonate, and the delivery mode which can best prevent this from happening is still unknown. Expert consensus has stated that there is no clear evidence that cesarean delivery prevents vertical transmission at the time of delivery (13). Whether vaginal delivery increases the risk of mother-tochild intrapartum transmission and whether uterine contraction could increase the possibility of the virus ascending needs to be further investigated.

Therefore, this review aims to determine which mode of delivery is better for preventing possible vertical transmission from COVID-19 positive pregnant women to the neonate.

\section{METHODS}

We wrote the review based on Preferred Reporting Items for Systematic Reviews and Meta-analyses (PRISMA) guidelines
(14). The protocol was registered in the International Prospective Register of Systematic Reviews (known as PROSPERO; registration number: CRD42020194049).

\section{Data Sources, Search Strategy, and Eligibility Criteria}

We conducted a comprehensive literature search of PubMed, Embase, Cochrane Library, Web of Science, Google Scholar, and the Chinese Biomedical Literature database (CBM) from 31 December 2019 (when COVID-19 was first reported from Wuhan, China) to 18 June 2020. We also searched the references of selected studies. We placed no limits or filters on the searches. Combinations of the following keywords and $\mathrm{MeSH}$ terms were used: 2019-nCov, COVID-19, coronavirus disease 2019, severe acute respiratory syndrome coronavirus 2, SARS-CoV2 , pregnancy, pregnant, gravidity, gestation, maternal, mothers, fetal, fetus, neonate, newborn, vertical transmission, maternalfetal transmission, intrauterine transmission, delivery. A detailed search strategy can be seen in Appendix 1. Eligibility criteria were randomized controlled studies, observational studies (including cohort, case-control studies, case series, and case reports), studies involving laboratory-confirmed and/or clinically diagnosed COVID-19 during pregnancy, studies involving neonates born to mothers with confirmed COVID-19 infection, studies with available clinical characteristics, including neonatal outcomes, clinical studies, studies reporting original data, studies reporting SARS-CoV-2 infected women who have delivered. Exclusion criteria were as follows: Studies involving mothers with suspected COVID-19 infection, studies with unreported neonatal outcomes, unpublished reports, studies suspected of including duplicate reporting, review, guidelines, opinions, and comments.

Suspected case defined as a person who meets the clinical AND epidemiological criteria (15):

\section{Clinical Criteria}

- Acute onset of fever AND cough; OR

- Acute onset of ANY THREE OR MORE of the following signs or symptoms: fever, cough, general weakness/fatigue, headache, myalgia, sore throat, coryza, dyspnoea, anorexia/nausea/vomiting, diarrhea, altered mental status (signs separated with a slash are to be counted as one sign). 


\section{Epidemiological Criteria}

- Residing or working in an area with a high risk of transmission of virus: closed residential settings, humanitarian settings such as camp and camp-like settings for displaced persons; anytime within the 14 days prior to symptom onset; OR

- Residing or travel to an area with community transmission anytime within the 14 days prior to symptom onset; OR

- Working in any health care setting, including within health facilities or within the community; any time within the 14 days prior to symptom onset.

A clinically diagnosed case was defined as a suspected case with manifestations with pneumonia image features on computerized tomography (CT) scan (Another potential cause of pneumonia was rule out before diagnosis) (16).

A laboratory-confirmed case was defined as a positive result to reverse transcriptase-polymerase chain reaction (RT-PCR) nasopharyngeal swab and/or antibody testing SARS-CoV-2 (15).

A positive result of antibody testing of SARS-CoV-2 was defined as elevated concentrations of immunoglobulin $\mathrm{M}$ (the normal IgM level: <10 AU/mL).

\section{Study Selection}

Two independent reviewers (B.W and H.W) evaluated articles for potential inclusion by screening titles and abstracts. The full texts of those identified as being relevant were assessed to determine eligibility for final inclusion. Between each assessment, we discussed the results to reach a consensus on interpreting the inclusion criteria. We resolved any disagreements regarding study eligibility by consensus, and a third reviewer (D.Z) was consulted, if necessary. If the information required to assess eligibility is unavailable or unclear, the relevant study authors were contacted for clarification. Duplicate publications were identified and removed using EndNote software version X7 (Clarivate Analytics). The identified paper(s) were analyzed using criteria based on the largest sample size, the maximum correspondence with the inclusion criteria, and minimal risk of bias. When a hospital had published their cases more than once, if the periods of recruitment overlapped, we included the paper with the biggest data to minimize the possibility of double counting.

\section{Data Extraction and Synthesis}

We extracted data from the studies selected for inclusion, as follows: general characteristics of included studies (author names, title, publication date, source of funding, and reported conflicts of interests), type of the study, sample size, study subject characteristics (demographic characteristics, gestational age, mode of delivery), outcome measures and analyses (neonatal outcomes, number of positive samples, maternal deaths). Two authors (H.X.Z.and H.L.) extracted the data independently and in duplicate. We resolved discrepancies through discussion to achieve a consensus. Study authors were contacted to obtain missing information or to clarify the information available. However, at the time of submission, we received no responses. The SARS-CoV-2 test positivity in neonates born to mothers with confirmed COVID-19 following different delivery modes was the primary outcome. Secondary outcomes were neonatal deaths and maternal deaths. Our search did not identify any randomized trials. We did a narrative synthesis of the findings when the meta-analysis was not possible or appropriate from the included studies.

\section{Risk of Bias and Grade Certainty Assessment}

The risk of bias was assessed using the Newcastle-Ottawa scale (NOS) for observational cohort and case-control studies, and Joanna Briggs Institute (JBI) critical appraisal tools for case reports and case series studies $(17,18)$. For cohort and casecontrol studies, there were three grouping items as follows: selection, comparability, exposure/outcomes. A study can be awarded a maximum of one star for each numbered item within the selection and outcome categories. A maximum of two stars can be given for comparability (17). More stars are equalling lower risk. Case reports and case series studies were categorized according to the percentage of positive answers to each of the questions. Low risk of bias indicated more than $70 \%$ of positive answers; moderate risk of bias ranged between 50 and 69\%, and high risk of bias represented $<49 \%$ of positive answers (19). We graded the certainty of evidence using the GRADE approach. We used the GRADEpro guideline development tool (GDT) app to rate evidence and present it in a summary of findings table (20).

\section{Data Analysis}

Characteristics of each study, and results were described and tabulated. We also performed additional sensitivity analyses to assess the robustness of our findings. Sensitivity analyses for the primary outcome and secondary outcomes included: (1) we excluded cases reported neonate with only elevated IgM levels for SARS-CoV-2 but negative for RT-PCR considering the possibility of false-positive results for the serological test (21); (2) we conducted subgroup analyses by pregnant women who were symptomatic or asymptomatic before delivery. Clinically, since an asymptomatic patient identified at screening might not have any delivery complications as opposed to a symptomatic one, where the mode of delivery might be because of maternal indication. Thus, perinatal transmission study might be biased; (3) the infection moment when pregnant women confirmed COVID-19 (i.e., infection on first, second, third trimester). All sensitivity analyses were considered exploratory. No other statistical analyses were anticipated.

\section{RESULTS}

We identified 880 studies, 94 full-text articles assessed for eligibility, including 21 duplicates (cases reported by one or more of the same hospitals and study dates overlap), three unreported neonatal outcomes, one withdrawn at the request of the author, one study reported pregnant women with suspected COVID-19 infection (Figure 1). The detailed information on these excluded studies can be seen in Appendix S7.

In total, sixty-eight studies from 21 countries that meet the eligibility were included in our systematic review. Studies were all observational in nature. We identified no randomized 


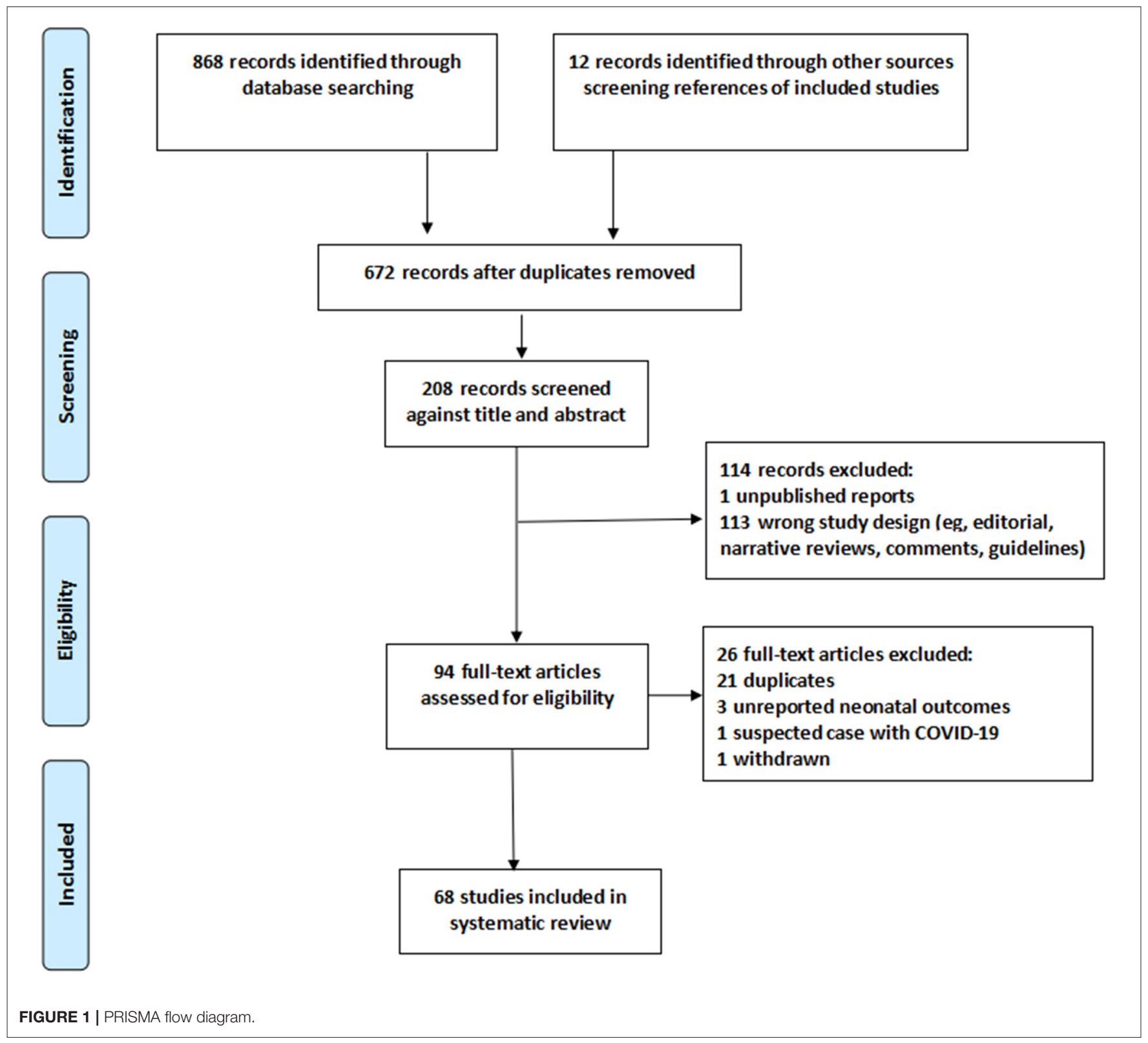

controlled trials in the search strategy. These were published from 6 February 2020 to 12 June 2020. Forty-one were case report studies, 22 were case series studies, four cohort studies, and one case-control study (Table 1).

Among the five comparative studies (cohort and casecontrol), one study compared maternal and neonatal outcomes of pregnant women with and without COVID-19 infections. Three studies compared the clinical course of pregnant women with mild, severe, or critical COVID-19 pneumonia. Only one cohort study estimates associations between delivery mode (vaginal vs. cesarean delivery) and maternal and neonatal outcomes among SARS-CoV-2-infected women giving birth. It was impossible to perform a meta-analysis in this systematic review. Thus, we did a narrative synthesis of the findings from the included studies.
The maternal age of the reported cases ranged from 16 to 48 years, gestational age at diagnosis ranged from 16 to 41 weeks. A total of 1,019 women and 1,035 neonates had detailed information on the delivery mode and infant infection status, including 14 sets of twins and one set of triplets. Among fifteen multiple pregnancies, one woman had a vaginal birth for twins, and the others had a cesarean section.

Of the 1,035 neonates, 618 (59.71\%) were born through cesarean section and 417 (40.29\%) through vaginal delivery (Table 2). SARS-CoV-2 infections were reported in 34/1,035 (3.29\%) neonates, included thirty-one RT-PCR positive neonates. The other three neonates had elevated levels of IgM for SARSCoV-2 but negative for RT-PCR. Of the 416 women who delivered vaginally, 9/417 (2.16\%) neonates tested positive for 
TABLE 1 | Characteristics of the included studies.

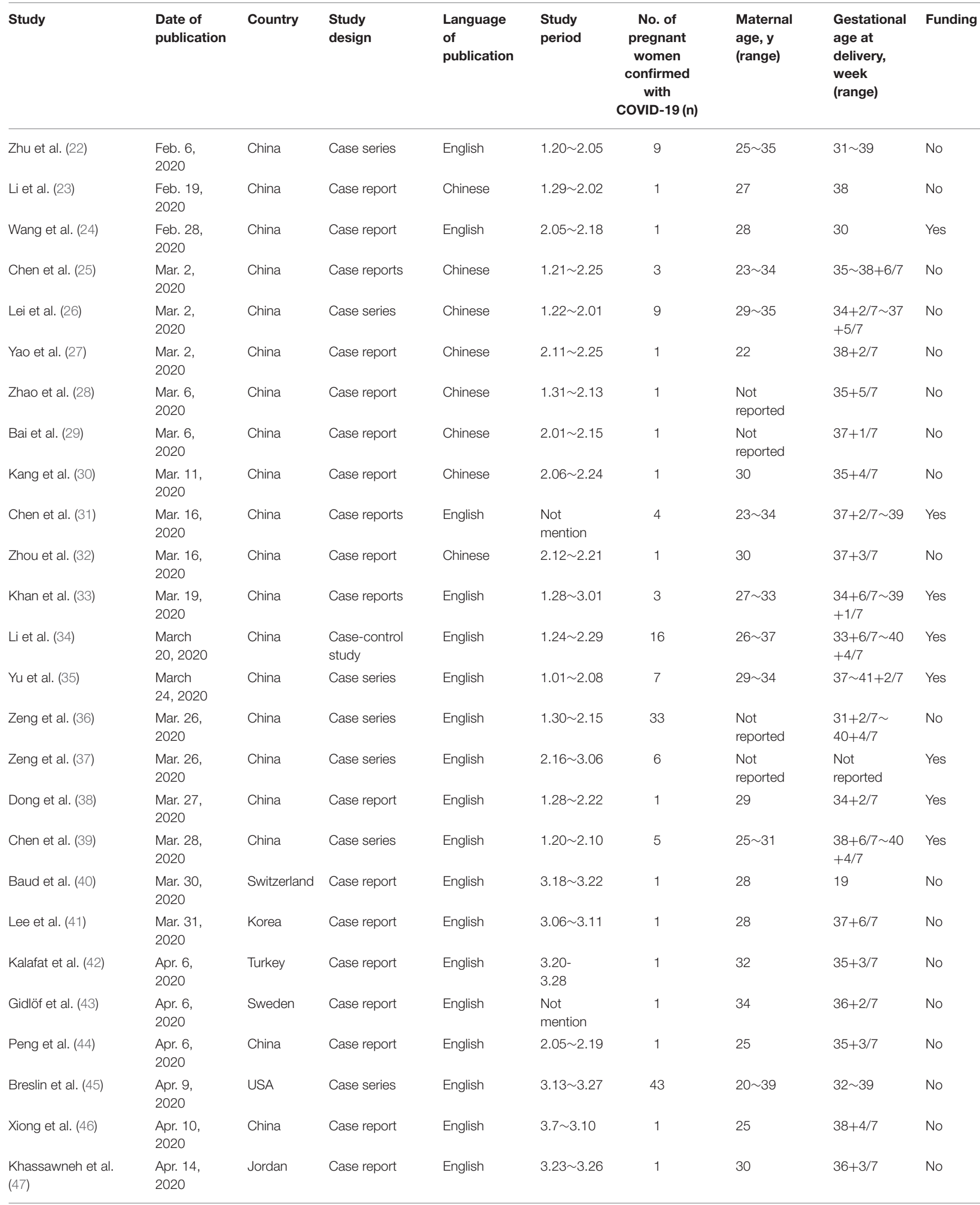


TABLE 1 | Continued

\begin{tabular}{|c|c|c|c|c|c|c|c|c|c|}
\hline Study & $\begin{array}{l}\text { Date of } \\
\text { publication }\end{array}$ & Country & $\begin{array}{l}\text { Study } \\
\text { design }\end{array}$ & $\begin{array}{l}\text { Language } \\
\text { of } \\
\text { publication }\end{array}$ & $\begin{array}{l}\text { Study } \\
\text { period }\end{array}$ & $\begin{array}{l}\text { No. of } \\
\text { pregnant } \\
\text { women } \\
\text { confirmed } \\
\text { with } \\
\text { CovID-19 (n) }\end{array}$ & $\begin{array}{l}\text { Maternal } \\
\text { age, y } \\
\text { (range) }\end{array}$ & $\begin{array}{l}\text { Gestational } \\
\text { age at } \\
\text { delivery, } \\
\text { week } \\
\text { (range) }\end{array}$ & Funding \\
\hline $\begin{array}{l}\text { Schnettler et al. } \\
(48)\end{array}$ & $\begin{array}{l}\text { Apr. 14, } \\
2020\end{array}$ & USA & Case report & English & $\begin{array}{l}3.24- \\
4.10\end{array}$ & 1 & 39 & $34+1 / 7$ & No \\
\hline Carosso et al. (50) & $\begin{array}{l}\text { Apr. 14, } \\
2020\end{array}$ & Italy & Case report & English & $\begin{array}{l}\text { Not } \\
\text { mention }\end{array}$ & 1 & 28 & 37 & No \\
\hline $\begin{array}{l}\text { González Romero } \\
\text { (51) }\end{array}$ & $\begin{array}{l}\text { Apr. 17, } \\
2020\end{array}$ & Spain & Case report & Spanish & $\begin{array}{l}\text { Not } \\
\text { mention }\end{array}$ & 1 & 44 & $29+2 / 7$ & No \\
\hline $\begin{array}{l}\text { Koumoutsea et al. } \\
\text { (52) }\end{array}$ & $\begin{array}{l}\text { Apr. 17, } \\
2020\end{array}$ & Canada & Case report & English & $\begin{array}{l}\text { Not } \\
\text { mention }\end{array}$ & 2 & $23 \sim 40$ & $\begin{array}{l}35+3 / 7 \sim 35 \\
+5 / 7\end{array}$ & No \\
\hline Lyra et al. (55) & $\begin{array}{l}\text { Apr. 20, } \\
2020\end{array}$ & Portugal & Case report & English & $\begin{array}{l}\text { Not } \\
\text { mention }\end{array}$ & 1 & 35 & $39+6 / 7$ & No \\
\hline $\begin{array}{l}\text { Al-kuraishy et al. } \\
\text { (56) }\end{array}$ & $\begin{array}{l}\text { Apr. 21, } \\
2020\end{array}$ & Iraq & Case report & English & $3.13 \sim 3.30$ & 1 & 25 & 30 & No \\
\hline Lu et al. (57) & $\begin{array}{l}\text { Apr. 24, } \\
2020\end{array}$ & China & Case report & English & $2.11 \sim 2.17$ & 1 & 22 & 38 & Yes \\
\hline Ferrazzi et al. (58) & $\begin{array}{l}\text { Apr. 27, } \\
2020\end{array}$ & Italy & Case series & English & $3.01 \sim 3.20$ & 42 & $21 \sim 44$ & $\begin{array}{l}\text { Not } \\
\text { reported }\end{array}$ & No \\
\hline $\begin{array}{l}\text { Hantoushzadeh } \\
\text { et al. (59) }\end{array}$ & $\begin{array}{l}\text { Apr. 28, } \\
2020\end{array}$ & Iran & Case series & English & $2.15 \sim 3.15$ & 9 & $\begin{array}{l}\text { Not } \\
\text { reported }\end{array}$ & $28 \sim 38+3 / 7$ & Yes \\
\hline $\begin{array}{l}\text { Pierce-Williams } \\
\text { et al. (64) }\end{array}$ & $\begin{array}{l}\text { May } 8 \\
2020\end{array}$ & USA & Cohort study & English & $4.20 \sim 5.05$ & 64 & $\begin{array}{l}\text { Not } \\
\text { reported }\end{array}$ & $\begin{array}{l}\text { Not } \\
\text { reported }\end{array}$ & No \\
\hline Valente et al. (65) & $\begin{array}{l}\text { May 10, } \\
2020\end{array}$ & Portugal & Case report & English & $3.17 \sim 3.19$ & 1 & 31 & 38 & No \\
\hline Liu et al. (66) & $\begin{array}{l}\text { May } 11 \\
2020\end{array}$ & China & Case series & English & $1.20 \sim 3.03$ & 51 & $\begin{array}{l}\text { Not } \\
\text { reported }\end{array}$ & $\begin{array}{l}35+1 / 7 \sim 41 \\
+2 / 7\end{array}$ & Yes \\
\hline Perrone et al. (67) & $\begin{array}{l}\text { May } 11 \\
2020\end{array}$ & Italy & Case reports & English & $3.01 \sim 4.30$ & 4 & $26 \sim 36$ & $\begin{array}{l}38+2 / 7 \sim 40 \\
+4 / 7\end{array}$ & No \\
\hline Baergen et al. (68) & $\begin{array}{l}\text { May } 12 \text {, } \\
2020\end{array}$ & USA & Case series & English & $\begin{array}{l}\text { Not } \\
\text { mention }\end{array}$ & 20 & $16 \sim 41$ & $\begin{array}{l}32+2 / 7 \sim 40 \\
+4 / 7\end{array}$ & No \\
\hline $\begin{array}{l}\text { Taghizadieh et al. } \\
\text { (69) }\end{array}$ & $\begin{array}{l}\text { May } 13 \text {, } \\
2020\end{array}$ & Iran & Case report & English & $\begin{array}{l}\text { Not } \\
\text { mention }\end{array}$ & 1 & 33 & 34 & No \\
\hline Patanè et al. (70) & $\begin{array}{l}\text { May } 14, \\
2020\end{array}$ & Italy & Case series & English & $3.05 \sim 4.21$ & 22 & $\begin{array}{l}\text { Not } \\
\text { reported }\end{array}$ & $\begin{array}{l}\text { Not } \\
\text { reported }\end{array}$ & No \\
\hline Kirtsman et al. (71) & $\begin{array}{l}\text { May } 14, \\
2020\end{array}$ & Canada & Case report & English & $\begin{array}{l}\text { Not } \\
\text { mention }\end{array}$ & 1 & 40 & $35+5 / 7$ & No \\
\hline Dória et al. (72) & $\begin{array}{l}\text { May } 15, \\
2020\end{array}$ & Portugal & Case series & English & $3.25 \sim 4.15$ & 10 & $27 \sim 40$ & $37 \sim 41$ & No \\
\hline
\end{tabular}


TABLE 1 | Continued

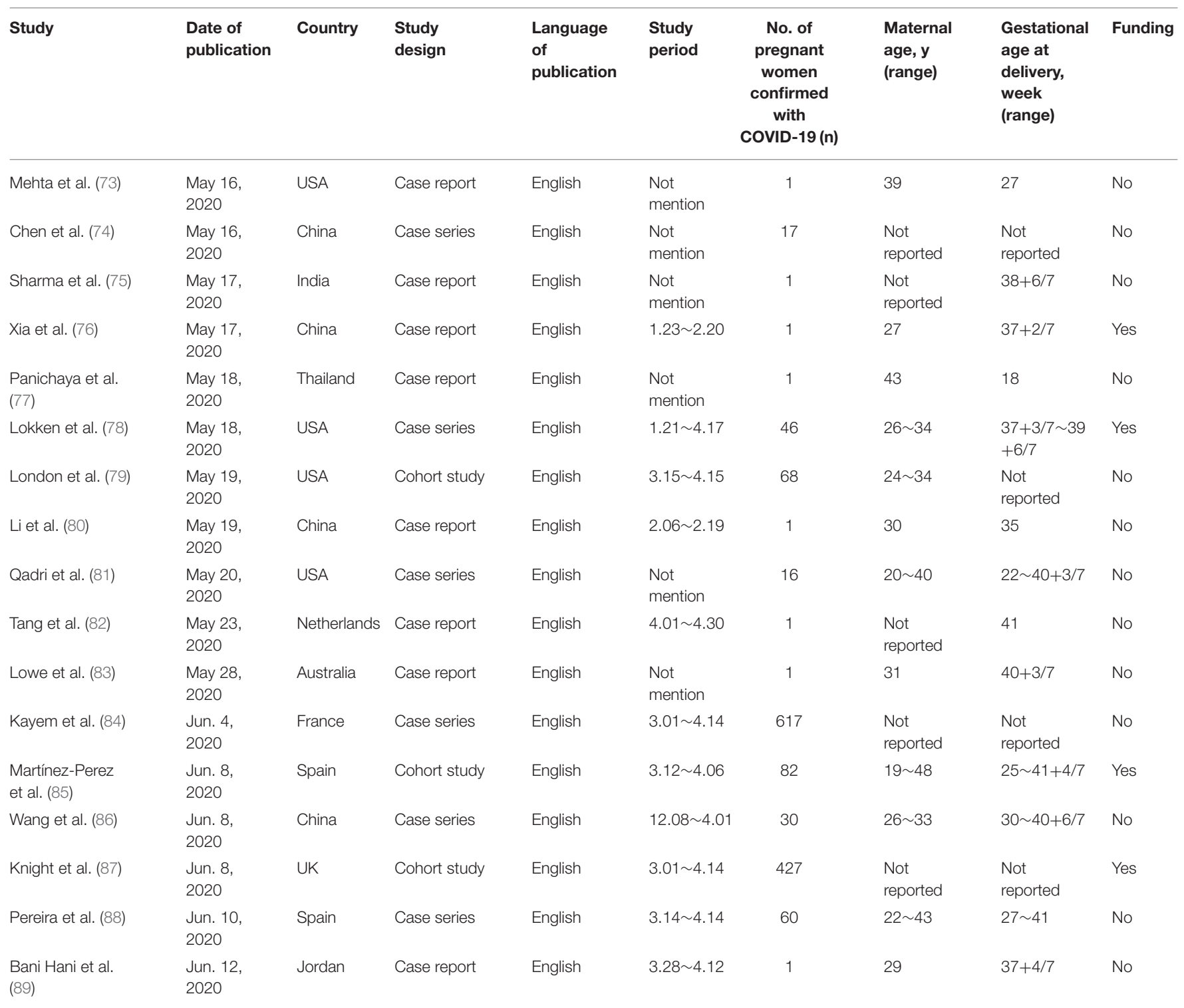

COVID-19. Of the 603 women who had a cesarean section, 25/618 (4.05\%) neonates were found to be positive for COVID19. A total of six neonatal deaths (including one set of twins) and nine stillbirths (including one set of twins) have been reported. Of babies born vaginally, $0 / 417(0.00 \%)$ neonatal deaths were reported compared with $6 / 618(0.97 \%)$ born by cesarean. A total of fourteen maternal deaths have been reported. Of women who delivered vaginally, $1 / 416(0.24 \%)$ maternal deaths were reported compared with $11 / 603(1.82 \%)$ delivered by cesarean. Two women died in the second trimester before delivery.

The risk of bias was mostly low-to-moderate after considering the observational designs. The results for each quality assessment by the study are presented in Appendix S2-S4.

Sensitivity analyses and subgroup analyses showed similar findings (Appendix S6). After excluded 3 (All three neonates were born through cesarean section) elevated levels of IgM for SARS-CoV-2 but negative for RT-PCR, 9/417 (2.16\%) neonates born by vaginally tested positive compared with 22/615 (3.58\%) neonates born by cesarean. Of the 394 women who were asymptomatic before delivery, 0/220 (0\%) maternal deaths were reported with vaginal delivery compared with $2 / 174$ (1.15\%) with cesarean delivery. Of the 625 women who were symptomatic before delivery, $1 / 196(0.51 \%)$ maternal deaths with vaginal delivery were reported compared with 9/429 (2.10\%) with cesarean delivery. Nearly all pregnant women delivered in the third trimester except three who delivered vaginally in the second trimester. Of women who delivered vaginally in the third trimester, $1 / 413(0.24 \%)$ maternal deaths were reported compared with $11 / 603(1.82 \%)$ delivered by cesarean in the third trimester. 
TABLE 2 | Maternal and neonatal outcomes by mode of delivery.

\begin{tabular}{lll}
\hline & $\begin{array}{l}\text { Vaginal delivery } \\
\text { No. (\%) }(\boldsymbol{n}=\mathbf{4 1 6})^{\mathbf{a}}\end{array}$ & $\begin{array}{l}\text { Cesarean delivery } \\
\text { No. (\%) }(\boldsymbol{n}=\mathbf{6 0 3})^{\mathbf{b}}\end{array}$ \\
\hline $\begin{array}{l}\text { Comorbidities } \\
\text { INDICATIONS FOR } \\
\text { CESAREAN DELIVERYd }\end{array}$ & $32(29.36 \%)$ & $60(27.91 \%)$ \\
$\begin{array}{l}\text { Due to obstetrical } \\
\text { indications }\end{array}$ & NA & $407(68.52 \%)$ \\
$\begin{array}{l}\text { Due to concern about } \\
\text { Covid-19 } \\
\text { MATERNAL OUTCOMES }\end{array}$ & NA & $187(31.48 \%)$ \\
$\begin{array}{l}\text { Maternal deaths } \\
\text { (secondary outcome) }\end{array}$ & & $11(1.82 \%)$ \\
$\begin{array}{l}\text { NEONATAL OUTCOMES } \\
\text { SARS-CoV-2 test positivity } \\
\text { (primary outcome) }\end{array}$ & $9(2.16 \%)$ & $25(4.05 \%)$ \\
$\begin{array}{l}\text { Neonatal deaths } \\
\text { (secondary outcome) }\end{array}$ & $0(0.00 \%)$ & $6(0.97 \%)$ \\
\hline
\end{tabular}

SARS-CoV-2 = severe acute respiratory syndrome coronavirus 2; NA, Not applicable.

a 416 pregnant women gave birth vaginally, including one set of twins.

${ }^{b} 603$ women gave birth by cesarean section, including one set of triplets and thirteen sets of twins.

${ }^{c}$ Detailed information on comorbidities was available for 324 pregnant women. Of the 109 women who delivered vaginally, 32 had one or more comorbidities. Of the 215 women who had a cesarean delivery, 60 had one or more comorbidities.

${ }^{d}$ Detailed information on the indication for cesarean section was available for 594 pregnant women.

e Excluding two women who died in the second trimester before delivery.

${ }^{f}$ Including 31 reverse transcriptase-polymerase chain reaction positive neonates and three elevated Immunoglobulin M levels for SARS-CoV-2 neonates.

${ }^{g}$ Excluding nine stillbirths.

\section{DISCUSSION}

Our results have shown that SARS-CoV-2 infections were rare in neonates. The rate of neonatal COVID-19 infection, neonatal deaths, and maternal deaths is no greater when the mother gave birth through vaginal delivery. Second, the vertical transmission of SARS-CoV-2 infection is possible in the third trimester but relatively low. Third, there has been duplicate reporting of pregnant women confirmed with COVID-19 from China and other countries.

Vertical transmission refers to how pathogens are transmitted from mother to offspring before and after birth. It includes transmission via placental blood during pregnancy, via the birth canal during delivery, and via breastmilk during postpartum breastfeeding (22). Placenta, cord blood, amniotic fluid, and vaginal secretion are intrauterine tissue samples that are essential for assessing vertical transmission (90). It is necessary to collect more kinds of specimens of SARS-CoV-2 infected pregnant women and their newborns to better evaluating the possibility of vertical transmission of SARS-CoV-2. It is noteworthy that these samples should be collected immediately after birth to avoid contamination condition (91). But very few of the included studies have met these criteria. Thus, additional good-quality studies with comprehensive serial tests from multiple specimens are urgently needed.
A total of 34 neonates were born in the third trimester with possible congenital SARS-CoV-2 infections were reported, suggesting that vertical transmission of COVID-19 is possible in the third trimester. Only three pregnant women gave birth vaginally in the second trimester. All neonates' samples tested negative by RT-PCR, suggesting that no intrauterine fetal infection occurred during the second trimester of pregnancy. A recent study suggested that the SARS-CoV-2-infected mother-tofetus transmission ratio will be significantly lower than that of the Zika virus. Because the expression of angiotensin-converting enzyme 2 (ACE2), which is the receptor that SARS-CoV-2 enters the cell, is deficient in all kinds of early maternal-fetal interface cells (92). And this may explain why SARS-CoV-2 can be found in human saliva rather than in vaginal secretions (93), which could also partially explain why the risk of intrauterine mother-to-child transmission for SARS-CoV-2 is low.

Thirty-one neonates tested positive for SARS-CoV-2 by RTPCR. The remaining three neonates had elevated IgM levels for SARS-CoV-2 but negative by RT-PCR. These three cases deserve additional details. Two studies reported three neonates with elevated IgM antibody values to SARS-CoV-2 born to mothers with COVID-19 from separate research teams in China $(37,94)$. All mothers wore masks during the cesarean delivery in negative pressure isolation rooms, and all medical staff wore protective suits and double masks. After birth, all infants were isolated from their mothers immediately. Neonatal blood was collected to test IgG and IgM antibodies to SARS-CoV-2 at 0 and $2 \mathrm{~h}$ after birth, respectively. However, all of the three neonatal respiratory samples tested negative for SARS-CoV-2 RNA, and there was no information provided by testing cord blood or placenta.

It is worth noting that IgM antibodies are not usually transferred from mother to fetus via the placenta because of the larger macromolecular structure (95). IgM is generally the first responded antibody that eliminating pathogens before sufficient IgG is produced (96). IgM positive results tend to indicate recent exposure to SARS-CoV-2. In contrast, the detection of COVID-19 IgG antibodies means virus exposure some time ago. IgM antibodies usually take days to appear after infection. IgM antibodies can be detected after a median of 5 days following the onset of symptoms (97). Most guidelines using nucleic acid tests as the gold standard for the diagnosis of COVID-19 due to the time lag between the onset of symptoms and IgM's appearance in serum and a lower sensitivity and specificity of serological tests $(98,99)$. Caution in interpreting these findings has been suggested, including the possibility of false-positive results (100). Thus, sensitivity analyses were performed by excluded reported elevated levels of IgM for SARS-CoV-2 but negative for RT-PCR. Sensitivity analyses showed the rate of neonatal COVID-19 infection still lower when the baby is born vaginally. Additional two sensitivity analyses showed similar findings regarding the moment of the infection and if pregnant women were symptomatic or asymptomatic before delivery.

Most of the guidelines for managing pregnant women with COVID-19 are based on previous SARS and MERS experience $(13,101,102)$. Suggestions on the selection of delivery methods in pregnancies with COVID-19 are contradictory (13). There were no confirmed cases of vertical transmission for SARS-CoV and 
MERS (103). Despite causing approximately one billion annual infections globally, the influenza virus has only a few cases of confirmed or suspected intrauterine fetal infections reported (104). Evidence for intrauterine influenza transmission exists from antigen and antibody testing in the infant brain, amniotic fluid, fetal heart, and cord blood (105). Nevertheless, which delivery mode is better for preventing vertical transmission from a pregnant woman with influenza to a neonate remains unknown.

While we have presented the data from a robust search of the literature for 1,019 women and 1,035 neonates, the given number did not control some confounding factors. For example, the mothers' COVID-19 infection severity was not presented due to the missing information of the included studies. What's more, the baseline conditions of pregnant women undergoing cesarean section and vaginal delivery are different, so we remind the reader to interpret the data in light of these biases would weaken the conclusions of current studies. The overall rate of cesarean section in the included studies was $59.18 \%(603 / 1,019)$, much higher than cesarean birth rates in the United States (31.9\%) and China (36.7\%) $(106,107)$. About $31.48 \%(187 / 594)$ of the cesarean deliveries were performed among women with COVID-19 due to concern about Covid-19 without obstetrical indications. According to a WHO report, (108) the rates of complications during pregnancy were similar between women who delivered vaginally $(18.36 \%)$ or by cesarean section (19.57\%). The neonatal death rates were similar between babies born vaginally $(0.59 \%)$ or by cesarean section $(0.79 \%)$. However, for maternal mortality, cesarean sections were associated with a significantly increased risk of maternal mortality than vaginal delivery (adjusted odds ratio 2.1, 95\% CI 1.7-2.6). Furthermore, cesarean delivery is associated with increased morbidity in the immediate postpartum period because of the increased risks of thromboembolic disease, blood loss, and infections (109). Currently, there is no sufficient evidence supporting that cesarean section improves outcomes among patients with COVID-19 and prevent possible vertical transmission from a pregnant mother confirmed with COVID19 to a neonate. Our findings suggest that COVID-19 infection should not be an indication for a cesarean birth. We advise that cesarean delivery be performed in women with COVID19 only after a careful evaluation of the disease severity and obstetrical indications. We believe our findings are reassuring and relevant to pregnant women confirmed with COVID-19 and obstetricians. Especially pregnant women with COVID-19 who want to give birth by vaginal delivery.

We identified 21 duplicate studies, some articles have been published in different languages, and some authors have reported features of pregnant women with COVID-19 from different perspectives. The detailed information on these duplicates studies can be seen in Appendix S7. There have several concerns about duplicate reporting of cases of COVID-19 been described $(110,111)$. Reporting the duplicates in different articles creates an inaccurate scientific record, precludes valid meta-analyses considering double-counting, and may affect understanding the disease and its epidemiology (110). To minimize the possibility of double counting, we reviewed the hospital and periods of recruitment. If they overlapped, only the study with the biggest data was included.

\section{LIMITATIONS OF STUDY}

Our article has some limitations. Firstly, we didn't search for the LILACS or SciELO database, which means the data on pregnant women from Latin America, the Caribbean region, and Brazil are scarce. Brazil has the third-largest number of COVID-19 cases after the United States and India. Secondly, we didn't perform analysis according to the severity of the COVID-19 infection of the mothers due to the missing information of the included studies. Pregnant women with more severe COVID-19 infection appear to prefer delivery by cesarean delivery rather than vaginal birth $(112,113)$. What's more, all patients in the study who give birth were recruited in their second and third trimester, so we were unable to ascertain the possibility of intrauterine vertical transmission during the first trimester. For example, rubella infection in the first trimester can affect more than $50 \%$ of fetuses via intrauterine infection. In contrast, by the end of the second trimester, the incidence rate is reduced by half (114).

\section{CONCLUSIONS}

The rate of neonatal COVID-19 infection, neonatal deaths, and maternal deaths is no greater when the mother gave birth through vaginal delivery. Based on the evidence available, there is no sufficient evidence supporting that the cesarean section is better than vaginal delivery in preventing possible vertical transmission from a pregnant mother confirmed with COVID-19 to a neonate. The mode of birth should be individualized and based on disease severity and obstetric indications. Additional good-quality studies with comprehensive serial tests from multiple specimens are urgently needed.

\section{DATA AVAILABILITY STATEMENT}

The original contributions presented in the study are included in the article/Supplementary Material, further inquiries can be directed to the corresponding authors.

\section{AUTHOR CONTRIBUTIONS}

JC had the idea for the article. DZ and HL contributed to the design of the search strategy. HW and BW did data selection. YY and RZ had roles in the assessment of the risk of bias in the included studies. All authors reviewed and approved the final version.

\section{SUPPLEMENTARY MATERIAL}

The Supplementary Material for this article can be found online at: https://www.frontiersin.org/articles/10.3389/fmed. 2021.634949/full\#supplementary-material 


\section{REFERENCES}

1. Zhu N, Zhang D, Wang W, Li X, Yang B, Song J, et al. A novel coronavirus from patients with pneumonia in China 2019. N Engl J Med. (2020) 382:72733. doi: 10.1056/NEJMoa2001017

2. WHO. Naming the Coronavirus Disease (COVID-19) and the Virus that Causes It. Available online at: https://www.who.int/emergencies/diseases/ novel-coronavirus-2019/technical-guidance/naming-the-coronavirusdisease-(covid-2019)-and-the-virus-that-causes-it (accessed at: June 18, 2020).

3. Zhong NS, Zheng BJ, Li YM, Poon LLM, Xie ZH, Chan KH, et al. Epidemiology and cause of severe acute respiratory syndrome (SARS) in Guangdong, People's Republic of China. Lancet. (2003) 362:13538. doi: 10.1016/S0140-6736(03)14630-2

4. Ksiazek TG, Erdman D, Goldsmith CS, Zaki SR, Peret T, Emery S, et al. A novel coronavirus associated with severe acute respiratory syndrome. $\mathrm{N} \mathrm{Engl}$ J Med. (2003) 348:1953-66. doi: 10.1056/NEJMoa030781

5. Zaki AM, Van Boheemen S, Bestebroer TM, Osterhaus ADME, Fouchier RAM. Isolation of a novel coronavirus from a man with pneumonia in Saudi Arabia. N Engl J Med. (2012) 367:1814-20. doi: 10.1056/NEJMoa12 11721

6. Wong SF, Chow KM, Leung TN, Ng WF, Ng TK, Shek CC, et al. Pregnancy and perinatal outcomes of women with severe acute respiratory syndrome. Am J Obstet Gynecol. (2004) 191:292-7. doi: 10.1016/j.ajog.2003.11.019

7. Shek CC, Ng PC, Fung GPG, Cheng FWT, Chan PKS, Peiris MJS, et al. Infants born to mothers with severe acute respiratory syndrome. Pediatrics. (2003) 112:e254. doi: 10.1542/peds.112.4.e254

8. Alfaraj SH, Al-Tawfiq JA, Memish ZA. Middle east respiratory syndrome coronavirus (MERS-CoV) infection during pregnancy: report of two cases \& review of the literature. J Microbiol Immunol Infect. (2019) 52:5013. doi: 10.1016/j.jmii.2018.04.005

9. Alserehi H, Wali G, Alshukairi A, Alraddadi B. Impact of middle east respiratory syndrome coronavirus (MERS-CoV) on pregnancy and perinatal outcome. BMC Infect Dis. (2016) 16:105. doi: 10.1186/s12879-016-1437-y

10. Liu H, Wang LL, Zhao SJ, Kwak-Kim J, Mor G, Liao AH. Why are pregnant women susceptible to COVID-19? An immunological viewpoint. J Reprod Immunol. (2020) 139:103122. doi: 10.1016/j.jri.2020.103122

11. Liu Y, Chen H, Tang K, Guo Y. Clinical manifestations and outcome of SARS-CoV-2 infection during pregnancy. J Infect. (2020) 48:43643. doi: $10.1016 /$ j.jinf.2020.02.028

12. Qiao J. What are the risks of COVID-19 infection in pregnant women? Lancet. (2020) 395:760-2. doi: 10.1016/S0140-6736(20)30365-2

13. Chen D, Yang H, Cao Y, Cheng W, Duan T, Fan C, et al. Expert consensus for managing pregnant women and neonates born to mothers with suspected or confirmed novel coronavirus (COVID-19) infection. Int J Gynaecol Obstet. (2020) 149:130-6. doi: 10.1002/ijgo.13146

14. Moher D, Liberati A, Tetzlaff J, Altman DG. Preferred reporting items for systematic reviews and meta-analyses: the PRISMA statement. BMJ. (2009) 339:b2535. doi: 10.1136/bmj.b2535

15. World Health Organization. WHO COVID-19 Case definition. Available online at: https://www.who.int/publications/i/item/WHO-2019-nCoVSurveillance_Case_Definition-2020.2 (accessed December 21, 2020).

16. China-National-Health-Commission. Diagnosis and Treatment of Pneumonitis Caused by New Coronavirus (version 5). Available online at: http://www.gov.cn/zhengce/zhengceku/2020-02/09/content_5476407. htm (accessed June 18, 2020).

17. Wells G, Shea B, O'Connell J. The Newcastle-Ottawa Scale (NOS) for Assessing the Quality of Nonrandomised Studies in Meta-analyses. Ottawa Health Research Institute Web site. Available online at: http://www3.med. unipmn.it/dispense_ebm/2009-2010/Corso\%20Perfezionamento\%20EBM_ Faggiano/NOS_oxford.pdf (accessed at: June 18, 2020).

18. Munn Z, Barker TH, Moola S, Tufanaru C, Stern C, McArthur A, et al. Methodological quality of case series studies: an introduction to the JBI critical appraisal tool. JBI Database System Rev Implement Rep. (2019) 18:2127-33. doi: 10.11124/JBISRIR-D-19-00099

19. Aromataris E, Munn Z. Joanna Briggs Institute Reviewer's Manual. The Joanna Briggs Institute (2017). Available online at: https://reviewersmanual. joannabriggs.org (accessed at: June 18, 2020).
20. Guyatt G, Oxman AD, Akl EA, Kunz R, Vist G, Brozek J, et al. GRADE guidelines: 1. Introduction-GRADE evidence profiles and summary of findings tables. J Clin Epidemiol. (2011) 64:383-94. doi: 10.1016/j.jclinepi.2010.04.026

21. Lisboa Bastos M, Tavaziva G, Abidi SK, Campbell JR, Haraoui LP, Johnston JC, et al. Diagnostic accuracy of serological tests for covid-19: systematic review and meta-analysis. BMJ. (2020) 370:m2516. doi: 10.1136/bmj.m2516

22. Zhu H, Wang L, Fang C, Peng S, Zhang L, Chang G, et al. Clinical analysis of 10 neonates born to mothers with 2019-nCoV pneumonia. Transl Pediatr. (2020) 9:51-60. doi: 10.21037/tp.2020.02.06

23. Li M, Xu M, Zhan W, Han T, Zhang G, Lu Y. Report of the first cases of mother and infant infections with 2019 novel coronavirus in Xinyang City Henan Province. Chin J Infect Dis. (2020) 38:E007.

24. Wang X, Zhou Z, Zhang J, Zhu F, Tang Y, Shen X. A case of 2019. Novel Coronavirus in a pregnant woman with preterm delivery. Clin Infect Dis. (2020) 71:844-6. doi: 10.1093/cid/ciaa200

25. Chen S, Huang B, Luo D, Li X, Yang F, Zhao Y, et al. Pregnancy with new coronavirus infection: clinical characteristics and placental pathological analysis of three case. Chin J Pathol. (2020) 49:418-23. doi: 10.3760/cma.j.cn112151-20200225-00138

26. Lei D, Wang C, Li C, Fang C, Yang W, Chen B, et al. Clinical characteristics of COVID-19 in pregnancy: analysis of nine cases. Chin J Perinat Med. (2020) 23:159-65. doi: 10.3760/cma.j.cn113903-20200216-00117

27. Yao L, Wang J, Zhao J, Cui J, Hu Z. Asymptomatic COVID-19 infection in pregnant woman in the third trimester: a case report. Chin J Perinat Med. (2020) 23.

28. Zhao Y, Lin Z, Mao X, Jiang X, Zhang W. Dyspnea in a newborn infant born to mother suffering from novel coronavirus pneumonia. Chin J Neonatol. (2020) 35:84-5.

29. Bai B, Gu Z, Hu S, et al. Pathogen survey in a mother with novel coronavirus pneumonia and her newborn infant. Chin J Neonatol. (2020) 35:85-6.

30. Kang $\mathrm{X}$, Zhang $\mathrm{R}$, $\mathrm{He} \mathrm{H}$, Yao Y, Zheng $\mathrm{Y}$, Wen $\mathrm{X}$, et al. Anesthesia management in cesarean section for a patient with coronavirus disease 2019. J Zhejiang Univ Med Sci. (2020) 49:249-52. doi: 10.3785/j.issn.1008-9292.2020.03.04

31. Chen Y, Peng H, Wang L, Zhao Y, Zeng L, Gao H, et al. Infants born to mothers with a new coronavirus (COVID-19). Front Pediatr. (2020) 8:104. doi: 10.3389/fped.2020.00104

32. Zhou R, Chen Y, Lin C, Li H, Cai X, Cai Z, et al. Asymptomatic COVID-19 in pregnant woman with typical chest CT manifestation: a case report. Chin J Perinat Med. (2020) 23:166-8.

33. Khan S, Peng L, Siddique R, Nabi G, Nawsherwan, Xue M, et al. Impact of COVID-19 infection on pregnancy outcomes and the risk of maternal-toneonatal intrapartum transmission of COVID-19 during natural birth. Infect Control Hosp Epidemiol. (2020) 41:748-50. doi: 10.1017/ice.2020.84

34. Li N, Han L, Peng M, Lv Y, Ouyang Y, Liu K, et al. Maternal and neonatal outcomes of pregnant women with COVID-19 pneumonia: a case-control study. Clin Infect Dis. (2020) 71:2035-41. doi: 10.1093/cid/ciaa352

35. Yu N, Li W, Kang Q, Xiong Z, Wang S, Lin X, et al. Clinical features and obstetric and neonatal outcomes of pregnant patients with COVID-19 in Wuhan, China: a retrospective, single-centre, descriptive study. Lancet Infect Dis. (2020) 20:559-64. doi: 10.1016/S1473-3099(20)30176-6

36. Zeng L, Xia S, Yuan W, Yan K, Xiao F, Sha J, et al. Neonatal earlyonset infection with SARS-CoV-2 in 33 neonates born to mothers with COVID-19 in Wuhan, China. JAMA Pediatr. (2020) 174:722-5. doi: 10.1001/jamapediatrics.2020.0878

37. Zeng H, Xu C, Fan J, Tang Y, Deng Q, Zhang W, et al. Antibodies in infants born to mothers with COVID-19 pneumonia. JAMA. (2020) 323:1848-9. doi: 10.1001/jama.2020.4861

38. Dong L, Tian J, He S, Zhu C, Wang J, Liu C, et al. Possible vertical transmission of SARS-CoV-2 from an infected mother to her newborn. JAMA. (2020) 323:1846-8. doi: 10.1001/jama.2020.4621

39. Chen S, Liao E, Cao D, Gao Y, Sun G, Shao Y. Clinical analysis of pregnant women with 2019 novel coronavirus pneumonia. J Med Virol. (2020) 92:1556-61. doi: 10.1002/jmv.25789

40. Baud D, Greub G, Favre G, Gengler C, Jaton K, Dubruc E, et al. Secondtrimester miscarriage in a pregnant woman with SARS-CoV-2 infection. JAMA. (2020) 323:2198-200. doi: 10.1001/jama.2020.7233 
41. Lee DH, Lee J, Kim E, Woo K, Park HY, An J. Emergency cesarean section on severe acute respiratory syndrome coronavirus 2 (SARS- CoV-2) confirmed patient. Korean J Anesthesiol. (2020) 73:347-51. doi: 10.4097/kja.20116

42. Kalafat E, Yaprak E, Cinar G, Varli B, Ozisik S, Uzun C, et al. Lung ultrasound and computed tomographic findings in pregnant woman with COVID-19. Ultrasound Obstetr Gynecol. (2020) 55:835-7. doi: 10.1002/uog.22034

43. Gidlöf S, Savchenko J, Brune T, Josefsson H. COVID-19 in pregnancy with comorbidities: more liberal testing strategy is needed. Acta Obstetr Gynecol Scand. (2020) 99:948-9. doi: 10.1111/aogs.13862

44. Peng Z, Wang J, Mo Y, Duan W, Xiang G, Yi M, et al. Unlikely SARS-CoV2 vertical transmission from mother to child: a case report. J Infect Public Health. (2020) 13:818-20. doi: 10.1016/j.jiph.2020.04.004

45. Breslin N, Baptiste C, Gyamfi-Bannerman C, Miller R, Martinez R, Bernstein $\mathrm{K}$, et al. COVID-19 infection among asymptomatic and symptomatic pregnant women: two weeks of confirmed presentations to an affiliated pair of New York City hospitals. Am J Obstetr Gynecol. (2020) 2:100118. doi: 10.1016/j.ajogmf.2020.100162

46. Xiong X, Wei H, Zhang Z, Chang J, Ma X, Gao X, et al. Vaginal delivery report of a healthy neonate born to a convalescent mother with COVID-19. J Med Virol. (2020) 92:1657-9. doi: 10.1002/jmv.25857

47. Khassawneh M, Khasawneh W, Zaghal LA, Hayajneh W, Abdelal F. The first Jordanian newborn delivered to COVID-19 infected mother with no evidence of vertical transmission: a case report. Res Square. (2020). doi: 10.21203/rs.3.rs-22938/v1

48. Schnettler WT, Al Ahwel Y, Suhag A. Severe acute respiratory distress syndrome in coronavirus disease 2019-infected pregnancy: obstetric and intensive care considerations. Am J Obstetr Gynecol. (2020) 2:100120. doi: 10.1016/j.ajogmf.2020.100120

49. Liu W, Wang J, Li W, Zhou Z, Liu S, Rong Z. Clinical characteristics of 19 neonates born to mothers with COVID-19. Front Med. (2020) 14:193-8. doi: 10.1007/s11684-020-0772-y

50. Carosso A, Cosma S, Borella F, Marozio L. Pre-labor anorectal swab for SARS-CoV-2 in COVID-19 pregnant patients: is it time to think about it? Euro J Obstetr Gynecol Reprod Biol. (2020) 249:98-9. doi: 10.1016/j.ejogrb.2020.04.023

51. González Romero D, Ocampo Pérez J, González Bautista L, Santana-Cabrera L. Pregnancy and perinatal outcome of a woman with COVID-19 infection. Rev Clin Espanola. (2020) 220:533-4. doi: 10.1016/j.rce.2020.04.006

52. Vlachodimitropoulou Koumoutsea E, Vivanti AJ, Shehata N, Benachi A, Le Gouez A, Desconclois C, et al. COVID-19 and acute coagulopathy in pregnancy. J Thromb Haemostasis. (2020) 18:1648-52. doi: 10.1111/jth.14856

53. Zamaniyan M, Ebadi A, Aghajanpoor S, Rahmani Z, Haghshenas M, Azizi S. Preterm delivery in pregnant woman with critical COVID-19 pneumonia and vertical transmission. Prenatal Diag. (2020). doi: 10.1002/pd.5713

54. Alzamora MC, Paredes T, Caceres D, Webb CM, Valdez LM, La Rosa M. Severe COVID-19 during Pregnancy and Possible Vertical Transmission. Am J Perinatol. (2020) 37:861-5. doi: 10.1055/s-0040-1710050

55. Lyra J, Valente R, Rosário M, Guimarães M. Cesarean section in a pregnant woman with COVID-19: first case in Portugal. Acta Med Portuguesa. (2020) 33:429-31. doi: 10.20344/amp.13883

56. Al-kuraishy H, Al-Maiahy T, Al-Gareeb A, Musa R, Ali Z. COVID-19 pneumonia in an Iraqi pregnant woman with preterm delivery. Asian Pac J Reprod. (2020) 9:156-8. doi: 10.4103/2305-0500.282984

57. Lu D, Sang L, Du S, Li T, Chang Y, Yang XA. Asymptomatic COVID-19 infection in late pregnancy indicated no vertical transmission. J Med Virol. (2020) 92:1660-4. doi: 10.1002/jmv.25927

58. Ferrazzi E, Frigerio L, Savasi V, Vergani P, Prefumo F, Barresi S, et al. Vaginal delivery in SARS-CoV-2-infected pregnant women in Northern Italy: a retrospective analysis. BJOG. (2020) 127:1116-1121. doi: 10.1111/1471-0528.16278

59. Hantoushzadeh S, Shamshirsaz AA, Aleyasin A, Seferovic MD, Aski SK, Arian SE, et al. Maternal death due to COVID-19. Am J Obstet Gynecol. (2020) 223:109.e1-e16. doi: 10.1016/j.ajog.2020.04.030

60. Penfield CA, Brubaker SG, Limaye MA, Lighter J, Ratner AJ, Thomas KM, et al. Detection of SARS-COV-2 in placental and fetal membrane samples. Am J Obstetr Gynecol. (2020) 2:100133. doi: 10.1016/j.ajogmf.2020.100133

61. Wu Y, Liu C, Dong L, Zhang C, Chen Y, Liu J, et al. Coronavirus disease 2019 among pregnant Chinese women: case series data on the safety of vaginal birth and breastfeeding. BJOG. (2020) 127:1109-15. doi: 10.1111/1471-0528.16276

62. Piersigilli F, Carkeek K, Hocq C, van Grambezen B, Hubinont C, Chatzis O, et al. COVID-19 in a 26-week preterm neonate. Lancet Child Adolesc Health. (2020) 4:476-8. doi: 10.1016/S2352-4642(20)30140-1

63. Blauvelt CA, Chiu C, Donovan AL, Prahl M, Shimotake TK, George RB, et al. Acute respiratory distress syndrome in a preterm pregnant patient with coronavirus disease 2019 (COVID-19). Obstetr Gynecol. (2020) 136:46-51. doi: 10.1097/AOG.0000000000003949

64. Pierce-Williams RAM, Burd J, Felder L, Khoury R, Bernstein PS, Avila $\mathrm{K}$, et al. Clinical course of severe and critical COVID-19 in hospitalized pregnancies: a US cohort study. Am J Obstetr Gynecol. (2020) 2:100134. doi: 10.1016/j.ajogmf.2020.100134

65. Polónia-Valente R, Moucho M, Tavares M, Vilan A, Montenegro N, Rodrigues T. Vaginal delivery in a woman infected with SARS-CoV-2 - The first case reported in Portugal. Euro J Obstetr Gynecol Reprod Biol. (2020) 250:253-4. doi: 10.1016/j.ejogrb.2020.05.007

66. Liu P, Zheng J, Yang P, Wang X, Wei C, Zhang S, et al. The immunologic status of newborns born to SARS-CoV-2-infected mothers in Wuhan, China. J Allergy Clin Immunol. (2020) 146:101-9.e1. doi: 10.1016/j.jaci.2020.04.038

67. Perrone S, Deolmi M, Giordano M, D'Alvano T, Gambini L, Corradi $\mathrm{M}$, et al. Report of a series of healthy term newborns from convalescent mothers with COVID-19. Acta Bio-medica. (2020) 91:251-5. doi: 10.23750/abm.v91i2.9743

68. Baergen RN, Heller DS. Placental pathology in Covid-19 positive mothers: preliminary findings. Pediatr Dev Pathol. (2020) 23:177-80. doi: $10.1177 / 1093526620925569$

69. Taghizadieh A, Mikaeili H, Ahmadi M, Valizadeh H. Acute kidney injury in pregnant women following SARS-CoV-2 infection: a case report from Iran. Resp Med Case Rep. (2020) 30:101090. doi: 10.1016/j.rmcr.2020. 101090

70. Patanè L, Morotti D, Giunta MR, Sigismondi C, Piccoli MG, Frigerio L, et al. Vertical transmission of COVID-19: SARS-CoV-2 RNA on the fetal side of the placenta in pregnancies with COVID-19 positive mothers and neonates at birth. Am J Obstetr Gynecol MFM. (2020) 2:100145. doi: 10.1016/j.ajogmf.2020.100145

71. Kirtsman M, Diambomba Y, Poutanen SM, Malinowski AK, Vlachodimitropoulou E, Parks WT, et al. Probable congenital SARSCoV-2 infection in a neonate born to a woman with active SARS-CoV-2 infection. CMAJ. (2020) 192:e647-e50. doi: 10.1503/cmaj.200821

72. Dória M, Peixinho C, Laranjo M, Mesquita Varejão A, Silva PT. Covid-19 during pregnancy: A case series from an universally tested population from the north of Portugal. Euro J Obstetr Gynecol Reprod Biol. (2020) 250:261-2. doi: 10.1016/j.ejogrb.2020.05.029

73. Mehta H, Ivanovic S, Cronin A, VanBrunt L, Mistry N, Miller R, et al. Novel coronavirus-related acute respiratory distress syndrome in a patient with twin pregnancy: a case report. Case Rep Women's Health. (2020) 27:e00220. doi: 10.1016/j.crwh.2020.e00220

74. Chen R, Zhang Y, Huang L, Cheng BH, Xia ZY, Meng QT. Safety and efficacy of different anesthetic regimens for parturients with COVID-19 undergoing Cesarean delivery: a case series of 17 patients. Canad J Anaesthes. (2020) 67:655-63. doi: 10.1007/s12630-020-01630-7

75. Sharma KA, Kumari R, Kachhawa G, Chhabra A, Agarwal R, Sharma A, et al. Management of the first patient with confirmed COVID-19 in pregnancy in India: from guidelines to frontlines. Int J Gynaecol Obstetr. (2020) 150:116-8. doi: 10.1002/ijgo.13179

76. Xia H, Zhao S, Wu Z, Luo H, Zhou C, Chen X. Emergency Caesarean delivery in a patient with confirmed COVID-19 under spinal anaesthesia. Br J Anaesthes. (2020) 124:e216-e8. doi: 10.1016/j.bja.2020.02.016

77. Panichaya P, Thaweerat W, Uthaisan J. Prolonged viral persistence in COVID-19 second trimester pregnant patient. Euro J Obstetr Gynecol Reprod Biol. (2020) 250:263. doi: 10.1016/j.ejogrb.2020.05.030

78. Lokken EM, Walker CL, Delaney S, Kachikis A, Kretzer NM, Erickson A, et al. Clinical characteristics of 46 pregnant women with a SARS-CoV-2 infection in Washington state. Am J Obstet Gynecol. (2020) 223:911.e1-e14. doi: 10.1016/j.ajog.2020.05.031

79. London V, McLaren R, Jr., Atallah F, Cepeda C, McCalla S, Fisher $\mathrm{N}$, et al. The relationship between status at presentation and outcomes 
among pregnant women with COVID-19. Am J Perinatol. (2020) 37:91-4. doi: 10.1055/s-0040-1712164

80. Li Y, Zhao R, Zheng S, Chen X, Wang J, Sheng X, et al. Lack of vertical transmission of severe acute respiratory syndrome coronavirus 2, China. Emerg Infect Dis. (2020) 26:1335-6. doi: 10.3201/eid2606.200287

81. Qadri F, Mariona F. Pregnancy affected by SARS-CoV-2 infection: a flash report from Michigan. J Mater Fetal Neonatal Med. (2020) 2020:1-3. doi: 10.1080/14767058.2020.1765334

82. Tang MW, Nur E, Biemond BJ. Immune thrombocytopenia due to COVID-19 during pregnancy. Am J Hematol. (2020) 95:E191-2. doi: 10.1002/ajh.25877

83. Lowe B, Bopp B. COVID-19 vaginal delivery - A case report. Austr N Z J Obstetr Gynaecol. (2020) 60:465-6. doi: 10.1111/ajo.13173

84. Kayem G, Lecarpentier E, Deruelle P, Bretelle P, Azria E, Blanc J, et al. A snapshot of the Covid-19 pandemic among pregnant women in France. J Gynecol Obstetr Hum Reprod. (2020) 2020:101826. doi: 10.1016/j.jogoh.2020.101826

85. Martínez-Perez O, Vouga M, Cruz Melguizo S, Acebal LF, Panchaud A, Muñoz-Chápuli $\mathrm{M}$, et al. Association between mode of delivery among pregnant women with COVID-19 and maternal and neonatal outcomes in Spain. JAMA. (2020) 324:296-9. doi: 10.1001/jama.2020.10125

86. Wang Z, Wang Z, Xiong G. Clinical characteristics and laboratory results of pregnant women with COVID-19 in Wuhan, China. Int J Gynaecol Obstetr. (2020) 150: 312-7. doi: 10.1002/ijgo.13265

87. Knight M, Bunch K, Vousden N, Morris E, Simpson N, Gale C, et al. Characteristics and outcomes of pregnant women admitted to hospital with confirmed SARS-CoV-2 infection in UK: national population based cohort study. BMJ. (2020) 369:m2107. doi: 10.1136/bmj.m2107 P

88. ereira A, Cruz-Melguizo S, Adrien M, Fuentes L, Marin E, Perez-Medina T. Clinical course of coronavirus disease-2019 in pregnancy. Acta Obstetr Gynecol Scand. (2020) 99:839-47. doi: 10.1111/aogs.13921

89. Bani Hani DA, Alsharaydeh I, Bataineh AM, Al Athamneh M, Qamileh I, Al-Baik A, et al. Successful anesthetic management in cesarean section for pregnant woman with COVID-19. Am J Case Rep. (2020) 21:e925512. doi: 10.12659/AJCR.925512

90. Cai J, Zhang Y, Tang M. New evidences that discard the possible vertical transmission of SARS-CoV-2 during pregnancy. Med Clin. (2020). doi: 10.1016/j.medcli.2020.09.021. [Epub ahead of print].

91. Wang C, Zhou YH, Yang HX, Poon LC. Intrauterine vertical transmission of SARS-CoV-2: what we know so far. Ultrasound Obstet Gynecol. (2020) 55:724-25. doi: 10.1002/uog.22045

92. Qing-Liang Z, Tao D, Li-Ping J. Single-cell RNA expression profiling of ACE2 and AXL in the human maternal-fetal interface. Reproduct Dev Med. (2020) 4:7-10. doi: 10.4103/2096-2924.278679

93. Xu H, Zhong L, Deng J, Peng J, Dan H, Zeng X, et al. High expression of ACE2 receptor of $2019-\mathrm{nCoV}$ on the epithelial cells of oral mucosa. Int $J$ Oral Sci. (2020) 12:8. doi: 10.1038/s41368-020-0074-x

94. Dong L, Tian J, He S, Zhu C, Wang J, Liu C, et al. Possible vertical transmission of SARS-CoV-2 from an infected mother to her newborn. JAMA. (2020) 323:1846-8.

95. Woo PCY, Lau SKP, Wong BHL, Tsoi H-w, Fung AMY, Chan K$h$, et al. Detection of specific antibodies to severe acute respiratory syndrome (SARS) coronavirus nucleocapsid protein for serodiagnosis of SARS coronavirus pneumonia. J Clin Microbiol. (2004) 42:23069. doi: 10.1128/JCM.42.5.2306-2309.2004

96. Pan Y, Li X, Yang G, Fan J, Tang Y, Zhao J, et al. Serological immunochromatographic approach in diagnosis with SARSCoV-2 infected COVID-19 patients. J Infect. (2020) 81:e2832. doi: 10.1016/j.jinf.2020.03.051

97. Guo L, Ren L, Yang S, Xiao M, Chang D, Yang F, et al. Profiling early humoral response to diagnose novel coronavirus disease (COVID-19). Clin Infect Dis. (2020) 71:778-85. doi: 10.1093/cid/ciaa310

98. Nielsen CM, Hansen K, Andersen HM, Gerstoft J, Vestergaard BF. An enzyme labelled nuclear antigen immunoassay for detection of cytomegalovirus IgM antibodies in human serum: specific and non-specific reactions. J Med Virol. (1987) 22:67-76. doi: 10.1002/jmv.1890220109

99. Bastian I, Waring L. The royal college of pathologists of Australasia (RCPA) position statement on COVID-19. Aust J Gen Pract. (2020) 49. doi: 10.31128/AJGP-COVID-09. [Epub ahead of print].

100. Kimberlin DW, Stagno S. Can SARS-CoV-2 infection be acquired in utero?: more definitive evidence is needed. JAMA. (2020) 323:1788-9.

101. Rasmussen SA, Smulian JC, Lednicky JA, Wen TS, Jamieson DJ. Coronavirus disease 2019 (COVID-19) and pregnancy: what obstetricians need to know. Am J Obstet Gynecol. (2020) 222:415-26. doi: 10.1016/j.ajog.2020. 02.017

102. Donders F, Lonnée-Hoffmann R, Tsiakalos A, Mendling W, Martinez de Oliveira J, Judlin P, et al. ISIDOG recommendations concerning COVID-19 and pregnancy. Diagnostics. (2020) 10:243. doi: 10.3390/diagnostics10040243

103. Schwartz DA, Graham AL. Potential maternal and infant outcomes from (Wuhan) Coronavirus 2019-nCoV Infecting Pregnant Women: lessons from SARS, MERS, and Other Human Coronavirus Infections. Viruses. (2020) 12:194. doi: 10.3390/v12020194

104. Schwartz DA, Dhaliwal A. Infections in pregnancy with covid-19 and other respiratory RNA virus diseases are rarely, if ever, transmitted to the fetus: experiences with coronaviruses, HPIV, HMPV RSV, and influenza. Arch Pathol Lab Med. (2020) 144:920-8. doi: 10.5858/arpa.2020-0211-SA

105. Conover PT, Roessmann U. Malformational complex in an infant with intrauterine influenza viral infection. Arch Pathol Lab Med. (1990) 114:535-8.

106. Martin JA, Hamilton BE, Osterman MJK, Driscoll AK. Births: final data for 2018. Natl Vital Stat Rep. (2019) 68:1-47. Available online at: https://www. cdc.gov/nchs/data/nvsr/nvsr68/nvsr68_13-508.pdf

107. The National Health Commission of China. Report on the Development of Maternal and Child Health in China (2019).

108. Lumbiganon P, Laopaiboon M, Gülmezoglu AM, Souza JP, Taneepanichskul S, Ruyan P, et al. Method of delivery and pregnancy outcomes in Asia: the WHO global survey on maternal and perinatal health 2007-08. Lancet. (2010) 375:490-9. doi: 10.1016/S0140-6736(09)61870-5

109. Sandall J, Tribe RM, Avery L, Mola G, Visser GH, Homer CS, et al. Shortterm and long-term effects of caesarean section on the health of women and children. Lancet. (2018) 392:1349-57. doi: 10.1016/S0140-6736(18) 31930-5

110. Bauchner H, Golub RM, Zylke J. Editorial concern-possible reporting of the same patients with COVID-19 in different reports. JAMA. (2020) 323:1256. doi: 10.1001/jama.2020.3980

111. Mofenson LM, Ciaranello A, LaHood N. More on clinical characteristics of pregnant women with covid-19 in Wuhan, China. N Engl J Med. (2020) 383:696. doi: 10.1056/NEJMc2016881

112. Qi H, Luo X, Zheng Y, Zhang H, Li J, Zou L, et al. Safe delivery for pregnancies affected by COVID-19. BJOG. (2020) 127:927-9. doi: 10.1111/1471-0528.16231

113. The Lancet. Emerging understandings of 2019-nCoV. Lancet. (2020) 395:311. doi: 10.1016/S0140-6736(20)30186-0

114. Bouthry E, Picone O, Hamdi G, Grangeot-Keros L, Ayoubi JM, VauloupFellous C. Rubella and pregnancy: diagnosis, management and outcomes. Prenat Diagn. (2014) 34:1246-53. doi: 10.1002/pd.4467

Conflict of Interest: The authors declare that the research was conducted in the absence of any commercial or financial relationships that could be construed as a potential conflict of interest.

Copyright (c) 2021 Cai, Tang, Gao, Zhang, Yang, Zhang, Wang, Liang, Zhang and $\mathrm{Wu}$. This is an open-access article distributed under the terms of the Creative Commons Attribution License (CC BY). The use, distribution or reproduction in other forums is permitted, provided the original author(s) and the copyright owner(s) are credited and that the original publication in this journal is cited, in accordance with accepted academic practice. No use, distribution or reproduction is permitted which does not comply with these terms. 